\title{
Market Capacity Model for the Supply Chain of Fruit and Vegetables in Indonesia - A Case Study on the Kramat Jati Central Wholesale Market in Jakarta -
}

\author{
Tetsuya Araki ${ }^{\mathrm{a}}$, Tatsuya Koyama ${ }^{\mathrm{a}}$, Yasuyuki Sagara ${ }^{\mathrm{a}}$ and Armansyah H. Tambunan ${ }^{\mathrm{b}}$ \\ ${ }^{a}$ The University of Tokyo, 1-1-1, Yayoi, Bunkyo-ku, Tokyo, 113-8657, Japan \\ ${ }^{\mathrm{b}}$ Bogor Agricultural University (IPB), P.O.Box 220, Kampus IPB Darmaga, Bogor, 16002, Indonesia
}

\begin{abstract}
SUMMARY
Indonesian national and regional policies on deregulating the supply chain of agricultural products among provinces after the economic crisis in 1997-98, brought a rapid increase in total amounts of fruit and vegetables that were transacted in most of wholesale markets, especially the Kramat Jati central wholesale market in Jakarta. Accordingly, relevant stakeholders found it difficult to manage the central market, striking an appropriate balance between the expansion of the profit from these transactions and the control of environmental damages in the market as well as surrounding areas. Nevertheless, no predictive models are available for the market capacity on the basis of engineering fieldwork in the market.
\end{abstract}

In this study, the Kramat Jati central wholesale market was selected as a case to analyze the supply chain of fruit and vegetables systematically by the PCM (Project Cycle Management) approach. First, stakeholders analysis was applied to draw a system of distribution and disposal for fruit and vegetables, that is, the social system that covers the distribution channel of fresh produce through the market as well as the channel of waste disposal in Jakarta. Then, problem analysis was also applied to investigate the true cause of insufficient rationalization for wholesalers and retailers in the market as the target groups, and then the results indicated that all problematic factors were rooted in insufficient funding resources for reconstructing the market's infrastructure. In particular, a technically-feasible issue was the vicious spiral of limited areas for sales and excessive incoming products. Thus, a mathematical model would be required to predict maximum capacity of the market.

A mathematical model has been proposed to predict maximum limits of the amount of incoming products and minimum limits of the area for each product in the market. The 
model was applied to the average amounts of dairy incoming products, and then the results indicated that the minimum area of the market should be $20 \%$ larger than the present one. The model calculation also demonstrated that the market capacity might be $15 \%$ larger than that in 2003, and 50\% larger in case incoming products are overstocked in all the passages of the market. The model would provide a practical way to improve the infrastructure as well as the whole supply chain for fruit and vegetables, especially in developing countries.

The market would become remarkably convenient for wholesalers after the completion of the renovation project, started in 2002, to enlarge its capacity; however, no radical programs were implemented to solve the issue of waste disposal due to financial and institutional limitations.

Furthermore, two issues of institutional changes were identified; bazaar institutions as well as institution for waste disposal, for which some political processes would be essential both inside the market and the outside. This implies that socially-vulnerable people should be paid more attention to in the system of distribution and disposal for fruit and vegetables, if all the stakeholders of the system hold a long-term vision to struggle these institutional changes.

\section{References:}

Bellah, N. Robert, Richard Madsen, William, M. Sullivan, Ann Swidler, and Steven M. Tipton (1991): The Good Society, Random House, New York

Geertz, Clifford (1978): The Bazaar Economy - Information and Search in Peasant Marketing, The American Economic Review, 68(2), 28-32.

Singgih, Shinta and Woods, Elizabeth (2003): Banana Supply Chains in Indonesia and Australia - Surviving Isolation from and Markets, Proceedings of International Farm Management Congress 2003.

Singgih, Shinta and Woods, Elizabeth (2004) Banana Supply Chains in Indonesia and Australia - Effects of Culture on Supply Chains, In Johnson, G. I. et al., Ed., Agri-product Supply Chain Management in Developing Countries, Proceedings of an International Workshop, Bali, Indonesia, 19-22 August 2003, Canberra, ACIAR Proceedings (in press). 